\title{
The stigma of mental illness in Southern Ghana: attitudes of the urban population and patients' views
}

\author{
Antonia Barke $\cdot$ Seth Nyarko $\cdot$ Dorothee Klecha
}

Received: 10 February 2010/Accepted: 13 September 2010/Published online: 26 September 2010

(C) The Author(s) 2010. This article is published with open access at Springerlink.com

\begin{abstract}
Purpose Stigma is a frequent accompaniment of mental illness leading to a number of detrimental consequences. Most research into the stigma connected to mental illness was conducted in the developed world. So far, few data exist on countries in sub-Saharan Africa and no data have been published on population attitudes towards mental illness in Ghana. Even less is known about the stigma actually perceived by the mentally ill persons themselves. Method A convenience sample of 403 participants (210 men, mean age $32.4 \pm 12.3$ years) from urban regions in Accra, Cape Coast and Pantang filled in the Community Attitudes towards the Mentally Ill (CAMI) questionnaire. In addition, 105 patients (75 men, mean age $35.9 \pm$ 11.0 years) of Ghana's three psychiatric hospitals (Accra Psychiatry Hospital, Ankaful Hospital, Pantang Hospital) answered the Perceived Stigma and Discrimination Scale.

Results High levels of stigma prevailed in the population as shown by high proportions of assent to items expressing authoritarian and socially restrictive views, coexisting with agreement with more benevolent attitudes. A higher level of education was associated with more positive attitudes on all subscales (Authoritarianism, Social Restrictiveness,
\end{abstract}

\footnotetext{
A. Barke $(\square)$

Georg Elias Müller Institute for Psychology,

University of Göttingen, Gosslerstr. 14,

37073 Göttingen, Germany

e-mail: abarke@uni-goettingen.de

S. Nyarko

Albert-Ludwigs-University, Freiburg, Germany

D. Klecha

Department of Forensic Psychiatry,

Medical Faculty, University of Bern, Bern, Switzerland
}

Benevolence and Acceptance of Community Based Mental Health Services). The patients reported a high degree of experienced stigma with secrecy concerning the illness as a widespread coping strategy. Perceived stigma was not associated with sex or age.

Discussion The extent of stigmatising attitudes within the urban population of Southern Ghana is in line with the scant research in other countries in sub-Saharan Africa and mirrored by the experienced stigma reported by the patients. These results have to be seen in the context of the extreme scarcity of resources within the Ghanaian psychiatric system. Anti-stigma efforts should include interventions for mentally ill persons themselves and not exclusively focus on public attitudes.

Keywords Stigma - Mental illness - Ghana - Population attitudes · Patients' perceptions

\section{Introduction}

\section{Stigma}

The stigmatisation of mental illness is a serious problem affecting patients and their relatives as well as institutions and health care personnel working with persons with mental illness. The more a mentally ill person feels stigmatised, the lower is their self-esteem [21], social adjustment [25] and quality of life [13, 29]. Stigma can adversely affect family relationships [17], lead to employment discrimination [35] and general social rejection [10]. Finally, Stigma also influences access to care, because people may be reluctant to seek help despite experiencing mental or emotional problems as this might be seen as an acknowledgement of weakness or failure [30, 31]. Negative and 
stigmatising public attitudes towards mentally ill persons therefore have direct implications for the prevention, treatment, rehabilitation and quality of life of those affected.

The present study is based on Link's and Phelan's model of stigma [20]. According to this model, stigmatisation occurs when four interrelated factors converge: (1) people distinguish and label human differences; (2) dominant cultural beliefs link the persons thus labelled to undesirable characteristics, i.e. to negative stereotypes; (3) labelled persons are placed in distinct categories and a degree of separation of "us" from "them" is created; (4) the labelled persons experience a loss of status and discrimination. The model distinguishes three types of stigma on the basis of their source. Individual discrimination consists in individual persons' negative behaviour towards members of a stigmatised group. Structural discrimination refers to the negative consequences of injustices inherent in social, political or legal structures or decisions. Self-stigmatisation is the process by which mentally ill persons adopt the stereotypes about people with mental illness prevailing in the society and consequently come to perceive themselves as socially unacceptable. Perceived stigma can result in a reluctance of the patient to seek help for mental illness [37]. Experiences and expectations of stigma may lead people with mental illness to seek ways of coping with the threat of rejection. The person may choose to conceal their illness or treatment history from employers, relatives, or potential partners to avoid the possibility of rejection or opt for limiting social interaction altogether [19]. Given the impact of experienced stigma, it is as important to investigate the mentally ill persons' perceptions and expectations of stigma as it is to obtain data from the communities.

\section{Psychiatric care in Ghana}

The Republic of Ghana has a population of approximately 20 million inhabitants, with the majority of the population living in the Southern and central parts of the country. The WHO estimates that approximately 650,000 persons in Ghana suffer from a severe mental disorder and further 2.17 million from moderate to mild mental disorders with a treatment gap of $98 \%$ of the affected population [39].

Ghana is a low income country based on the World Bank 2004 criteria and has an adult literacy rate of $54.1 \%$ [15]. The health expenditure is $4.5 \%$ of Ghana's gross national product (US, 15.2\%) [15], the government health budget is $1.4 \%$ (amounting to $31 \$$ per head and year), the remainder being paid for by external donors or user fees [39]. Only $0.5 \%$ of the health budget is spent on mental health (US, 6\%) [15]. Ghana has 0.08 psychiatrists per 100,000 inhabitants (US, 13.7), 10.3 psychiatric beds (US, 77) [15] and three public psychiatric hospitals, all located in the South of the country: Accra Psychiatric Hospital, Pantang Hospital and Ankaful Hospital. The capacity of Accra Psychiatric Hospital is 800 beds, but the hospital accommodates 1,200 and more patients [8, 16, 39]. Pantang Hospital and Ankaful Hospital cannot use their capacity of 500 beds each and accommodate only 450 and 300 patients, respectively, due to an insufficient number of health workers [39].

The Ghanaian Ministry of Health estimates that 70-80\% of Ghanaians use traditional medicine as first-line treatment with the concomitant problem of ensuring the quality of care [39]. Scarcity of mental health resources or lack of money is an important factor in the choice of traditional sources of help, but limited knowledge about mental illness and causal attributions of illness to supernatural forces as well as stigma associated with psychiatric treatment may also play a role $[7,27,28]$. The informal sector comprises an estimated 45,000 traditional healers and church facilities throughout the country [27].

Attitudes towards mental illness in sub-Saharan Africa

A recent review of population studies on the attitude towards people with mental illness [5] showed that most of the 61 articles published between 1990 and 2004 investigated the attitudes in European countries and other developed western nations. Only $15 \%$ of the studies reviewed were devoted to non-western countries and research carried out in Africa was dramatically underrepresented with just one study from Ethiopia.

The few studies conducted in Africa reported data from Nigeria and Ethiopia and showed that stigma regarding mental illness is widespread. A representative survey based on a questionnaire developed for the World Psychiatric Association's Programme to Reduce Stigma and Discrimination Because of Schizophrenia was conducted in three Yoruba-speaking communities in Nigeria $(n=2,040$ respondents, response rate $74.2 \%$ ). The study found predominantly negative views on mental illness, spread evenly across all social strata and independent of sex or age [14]. A high level of social distance was also found by Adewuya and Makanjuola [3] for the general Nigerian population and among a random sample of Nigerian university students [2].

Mulatu [23] used vignettes to collect attitudes towards 10 physical and mental illnesses in the Ethiopian population and found marked differences in attitude depending upon the illness characteristics. The diagnoses with the strongest stigma attached were leprosy, schizophrenia and tuberculosis, with less than $20 \%$ of the participants prepared to work with, be friends with or marry a person with schizophrenia. Deribew and Tamirat [11] also found negative attitudes towards mentally ill persons in their vignette study of the Ethiopian population. 
Attitude towards mental illness in Ghana

As in other sub-Saharan countries, in Ghana stigmatisation of mental illness is a serious problem permeating the mental health system [16, 27, 28]. Most evidence for this is based on statements of mental health personnel. Dr. Yaw Osei when first establishing psychiatric services in Kumasi at the Komfo Anokye Teaching Hospital, resorted to calling it "Headache Clinic" as mental illness was considered taboo in the prevailing Ashanti culture [16]. In a qualitative study, Quinn [26] interviewed family carers of mentally ill persons. He reported that a recurring topic of the interviews was that many relatives of mentally ill persons were worried about stigma and negative attitudes from society and the extended family, although supportive attitudes were also experienced.

The only existing study concerning the attitudes of the Ghanaian population was conducted by Ngissah in 1975 [24]. Ngissah compared 564 American High School and College students from Sacramento (California) with 280 Ghanaian High School and College Students from Accra and found more negative and rejecting attitudes towards mentally ill persons in the Ghanaian sample. $57.9 \%$ of the Ghanaian respondents held the view that mental illness in the family brings shame on the family name and $57.5 \%$ that it is wise to keep it a secret as much as possible. $60.4 \%$ of the Ghanaian participants felt that mental illness is not an illness like other illnesses, $78.9 \%$ agreed that patients in mental hospital are like children and $71.8 \%$ subscribed to the opinion that anyone hospitalized for a mental illness should be banned from voting.

The stigmatisation often leads to dramatic social consequences for the persons concerned. For example, about 70 patients treated by the Ankaful Psychiatric Hospital in Ghana have been abandoned by their families after their discharge from the hospital. (E. Blankson, personal communication, 10 August 2007, S.N.). The situation in other hospitals is similar; in Pantang Psychiatric Hospital, a special Vagrant Ward was created for patients who have been rejected by their families because of stigma. The General Secretary of the Ghanaian Medical Association estimated that a third of patients on admission in the Accra Psychiatric Hospital are patients who have been treated and discharged, but whose relations have refused to readmit them to the family [33].

Patients' views

Botha, Koen and Niehaus [9] used the Internalized Stigma of Mental Illness Scale (ISMI) to investigate stigma as experienced by South African patients with schizophrenia $(n=100)$. The results indicated a high overall level of stigma with $65 \%$ of the participants agreeing to the statement that they were discriminated against due to their psychiatric illness. Of the patients, 58\% reported verbal abuse (name calling) and $39 \%$ had even experienced physical abuse because of their illness [9]. Three quarters of family members of persons diagnosed with schizophrenia or affective disorders $(n=178)$ in Ethiopia also expressed concern about stigma [32].

Since no data are available regarding the question whether, and if so, how much, stigma is experienced by Ghanaians with mental illness, their perceptions were included in the present study.

With the present study we aim to contribute to the scant data on the attitudes towards mentally ill persons in subSaharan Africa, and more specifically in Ghana. We collected data in southern Ghana on:

1. Public attitudes toward mentally ill people in three areas, namely Accra, Pantang and Ankaful.

2. Perceptions of patients of Ghana's three public psychiatric hospitals with regard to stigma and strategies for coping with it.

\section{Method}

\section{Participants}

Two independent surveys were conducted: one among members of the general population and one among patients of the three psychiatric hospitals.

\section{Population}

A convenience sample was recruited using house-to-house interviewing and interviews in the streets in urban areas of three major Southern cities: Cape Coast, Pantang and Accra. The main ethnic group in this region are the Akan and the prevailing religious denomination is Christian. All members of each household who were 18 and above received an explanation regarding the purpose of the research and were asked whether they wished to participate. In total, 405 persons were invited to take part. Two of those approached declined participation. The final population sample consisted of 403 persons (210 men, 193 women) with a mean age ( \pm standard deviation) of $32.4 \pm 12.3$ years. The participants stated the following occupations: 62 were students, 80 were traders, 152 manual labourers, 54 teachers and 46 public servants; 9 persons did not state their occupation.

\section{Patients}

In-patients and day-care patients of Ghana's three psychiatric hospitals (Accra Psychiatric Hospital, Ankaful Hospital 
and Pantang Hospital) were approached and the nature and purpose of the study explained. Prior to the survey, the permission of the Ghanaian Ministry of Health was obtained. All persons who were currently patients in these hospitals were eligible to participate regardless of their diagnosis. Patients who were not able to take part in the brief interview (approximately $15 \mathrm{~min}$ ) because they were too agitated, acutely psychotic or too much under the influence of sedating medication were excluded. 105 patients were invited to participate and all those approached followed the invitation. The final sample consisted of 105 patients (75 men, 29 women, one person's sex was not recorded) with a mean age of $35.9 \pm 11.0$ years.

\section{Measures}

Community attitudes towards mentally ill persons were measured using the Community Attitude towards the Mentally Ill scale (CAMI) [36]. The scale includes 40 items to be rated on a five-point Likert scale from 1 (strongly agree) to 5 (strongly disagree) and is organized into four a priori subscales of ten items each: Authoritarianism (AU), Benevolence (BE), Social Restrictiveness (SR) and Community Mental Health Ideology (CMHI). Authoritarianism refers to a view of the mentally ill person as someone who is inferior and requires supervision and coercion. Benevolence corresponds to a humanistic and sympathetic view of mentally ill persons. Social Restrictiveness covers the belief that mentally ill patients are a threat to society and should be avoided. Community Mental Health Ideology concerns the acceptance of mental health services and the integration of mentally ill patients in the community. Taylor and Dear [36] report satisfactory (AU, $\alpha=0.68$ ) to good values (BE, $\alpha=0.76$, SR, $\alpha=0.80, \mathrm{CMHI}, \alpha=0.88$ ) for the internal consistency of the subscales. Unfortunately, due to a technical oversight, two items were omitted in the present study: AU Item 7 (The mentally ill should not be treated as outcasts of society) and BE Item 9 (There are sufficient existing services for the mentally ill).

The interviews were carried out by one of the authors (S.N.) with the help of five assistants trained for that purpose. The original English version of the CAMI was used as English is the official language in Ghana. Participants who had difficulty understanding English constituted a small minority $(<10 \%)$. For them the native trilingual interviewer (S.N.) translated the questions into Twi or Fanti as required. The central term "mental illness" was translated as "Abodam" (Twi) and "Bodam" (Fanti). Both terms have the same scope as the English term "mental illness". We calculated the internal consistencies (Cronbach's Alpha) of the CAMI subscales in our data set and found them to be lower than the original, but still acceptable for the subscales BE $(\alpha=0.71)$, SR $(\alpha=0.73)$ and CMHI $(\alpha=0.75)$ and poor for the subscale AU $(\alpha=0.31)$.

Perceived stigma was measured with three subscales of Link's Stigma Scale, Perceived Devaluation and Discrimination (PDD) [18, 22], Secrecy (SE) and Withdrawal (WI) [22]. The PDD includes 12 items, which assess perceived devaluation and discrimination by describing everyday experiences the person may have had or attitudes they may have encountered or may expect to encounter, whereas the other two subscales are concerned with possible strategies in reaction to expected or experienced rejection. Secrecy (9 items), measures the propensity of the person to conceal their mental illness and psychiatric treatment from others and Withdrawal ( 8 items), captures whether the person withdraws from the contact of persons without psychiatric disorders and prefers to associate with persons who also suffer from mental illness. Internal consistencies for the subscales were moderate with values for Cronbach's Alpha ranging from 0.69 to 0.87 (PDD, $\alpha=0.76$ [18]; SE, $\alpha=0.84-0.87$; WI, $\alpha=0.69-0.70,[22])$. In the original, the items were rated on a 6-point Likert scale from "strongly disagree" to "strongly agree". For the present study, the answer format was changed to a dichotomous "yes"/"no" format, since the questionnaire was administered as a standardized interview and the authors wished to reduce the demands placed on the participants. The instrument was used in the original English version; for the small minority of participants who had difficulty understanding English, the same procedure as described above was applied. In order to ascertain that the change in answer format and the translations had not compromised the instrument, we computed the internal consistencies (Cronbach's Alpha) for the subscales on the basis of our data. The internal consistencies PDD $(\alpha=0.73)$ and SE $(\alpha=0.82)$ were acceptable and comparable to that of the original despite the change in answer format, whereas for the subscale WI the internal consistency $(\alpha=0.49)$ was lower than that of the original.

Statistical methods

\section{Population sample}

Mean scores were computed for all subscales. Since this was the first study of attitudes towards mentally ill persons in Ghana, in addition detailed frequencies for the individual items are reported.

In order to ascertain whether there were any sex differences, we conducted independent sample $t$ tests (twotailed) comparing men and women with regard to the subscales as well as with regard to individual items. 
The influence of age was examined with correlations on subscale level and on item level.

In order to test the influence of education the participants were divided into two groups on the basis of the education required for their stated occupation, basic education only and secondary education and higher. Independent $t$ tests were calculated for each of the CAMI subscales (AU, BE, SR, CMHI).

\section{Patient sample}

The percentage of affirmative answers for each individual item was computed for an item-wise report. The influence of age was tested for each subscale by means of correlation and the influence of sex by means of independent $t$ tests.

All reported correlations are Pearson product moment correlations. If Levene's test indicated in the case of a $t$ test that equality of variance was violated, the values for the Welch test [38] are reported and the note "equal variances not assumed" added. For all $t$ tests, Cohen's $d$ is reported as a measure of effect size if appropriate.

\section{Results}

\section{Population}

Mean scores for each item of the subscales as well as the detailed frequencies and means for the individual items are reported in Table 1. In the following, only the main results are summarized.

On the causes and nature of mental illness, a majority of participants $(57.1 \%)$ rejected (aggregate of "disagree" and "strongly disagree") the view that mental illness is an illness like any other (AU6), rather it was seen as a consequence of lack of self-discipline and will power (AU1) by $61.2 \%$ of participants. Although virtually anyone may become ill (60.9\%, AU10), it was generally believed $(79.7 \%)$ that it is easy to tell persons with mental illness from 'normal' people (AU3).

Regarding the personal distance to persons with mental illness, only a minority (22.9\%) endorsed the statement that it is best to avoid persons with mental illness (BE10). This positive attitude extended to potential marriage with only $27.6 \%$ agreeing that it would be foolish for a woman to marry a man who has suffered from mental illness $(57.4 \%$ rejected this view). Although $54.6 \%$ assented to the statement that no one has the right to exclude the mentally ill from their neighbourhood (SR8), $42.1 \%$ believed that the mentally ill should be isolated from the community (SR2) and $39.7 \%$ would not want to live next door to someone who has been mentally ill (SR4). 50.7-54.8\% thought that the risks of mental patients living within residential neighbourhoods are too great (CMHI8, 9). However, locating mental health services in residential areas was not regarded as dangerous by $76.9-80.0 \%$ of the respondents (CMHI5, 10).

In general, the participants felt that mentally ill persons deserve sympathy (72.4\%, BE6), should not be denied their individual rights $(58.3 \%$, SR6) and have for too long been the subject of ridicule $(50.4 \%, \mathrm{BE} 1)$. The society ought to adopt a more tolerant attitude $(66.8 \%, \mathrm{BE} 3)$ and although a majority $(56.3 \%)$ judged that the mentally ill are a burden on society (BE7), the responsibility to provide the best possible care for the mentally ill was widely acknowledged (80.3\%, BE5). Spending tax money for that purpose was endorsed by $63.3 \%$ (BE2) if the item was positively phrased, but only by $23.3 \%$ in its inverted form (BE8).

\section{Sex and age}

Sex differences for the subscales were investigated with $t$ tests, revealing a sex difference for the subscale AU with women $(2.43 \pm 0.52)$ endorsing the authoritarian views contained in this subscale more strongly than men $(2.55 \pm 0.46), t(401)=2.45, p<0.05, d=0.24$.

In order to examine the influence of age, correlations of subscale means and age were computed. A small correlation $(r=-0.13, p<0.05)$ was found for the subscale SR, indicating that social restrictiveness slightly decreased with age.

\section{Education}

Dividing the participants in two groups, basic $(n=162)$ and secondary education $(n=232)$, on the basis of the education required for their occupation, small to medium differences were found, indicating that persons with secondary education tended to hold more positive views on persons with mental illness than those with only basic education. More educated persons were less authoritarian $(t(392)=3.39, p<0.005, d=0.35)$ and less socially restrictive $[t(359.04)=4.75, p<0.005, d=0.50$, equal variances not assumed] than persons with only basic education. They also expressed more benevolent views than the less educated participants $t(392)=3.45, p<0.005$, $d=0.36$, and subscribed more strongly to the CMHI than those with basic education, $t(392)=3.12, p<0.005$, $d=0.33$ (see Fig. 1 for details).

\section{Patients}

The perceived stigma is extensive (see Table 2 for percentage of agreement for each item). The highest agreement commanded statements expressing the view that mentally ill persons were regarded as inferior by the majority of 
Table 1 Frequencies, means and standard deviations for the items of the CAMI $(n=403)$

\begin{tabular}{ll}
\hline Item & $\begin{array}{l}\text { Strongly } \\
\text { agree/agree }(\%) \\
(\%)\end{array}$
\end{tabular}

Authoritarianism (AU)

One of the main causes of mental illness is a lack of self-discipline and will power 61.15 (AU1)

The best way to handle the mentally ill is to keep them behind locked doors (AU2) 47.76

There is something about the mentally ill that makes it easy to tell them from $\quad 79.70$ normal people (AU3)

A soon as a person shows signs of mental disturbance, he should be hospitalized (AU4)

Mental patients need the same kind of control and discipline as a young child (AU5)

Mental illness is an illness like any other (AU6)

Less emphasis should be placed on protecting the public from the mentally ill (AU8)

Mental hospitals are an outdated means of treating the mentally ill (AU9)

Virtually anyone can become mentally ill (AU10)

Benevolence (BE)

The mentally ill have for too long been the subject of ridicule (BE1)

More tax money should be spent on the care and treatment of the mentally ill (BE2)

We need to adopt a far more tolerant attitude towards the mentally ill in our society (BE3)

Our mental hospitals seem more like prisons than like places where the mentally ill 54.75 can be cared for (BE4)

We have a responsibility to provide the best possible care for the mentally ill (BE5)

The mentally ill don't deserve our sympathy (BE6)

The mentally ill are a burden on society (BE7)

Increased spending on mental health services is a waste of tax Cedis (BE8)

It is best to avoid anyone who has mental problems (BE10)

Social Restrictiveness (SR)

The mentally ill should not be given any responsibility (SR1)

The mentally ill should be isolated from the rest of the community (SR2)

A woman would be foolish to marry a man who has suffered from mental illness, even though he seems fully recovered (SR3)

I would not want to live next door to someone who has been mentally ill (SR4)

Anyone with a history of mental problems should be excluded from taking public office (SR5)

The mentally ill should not be denied their individual rights (SR6)

Mental patients should be encouraged to assume the responsibilities of normal life (SR7)

No one has the right to exclude the mentally ill from their neighbourhood (SR8)

The mentally ill are far less a danger than most people suppose (SR9)

Most women who were once patients in a mental hospital can be trusted as babysitters (SR10)

\section{Community Mental Health Ideology (CMHI)}

Residents should accept the location of mental health facilities in their neighbourhood (CMHI1)

The best therapy for many mental patients is to be part of a normal community (CMHI2)
79.25

68.25

31.17

23.61

32.66

60.90

50.38

63.29

66.92

80.34

56.27

22.86

25.37

41.60

42.14

27.56

38.13

34.73

58.30

62.72

54.59

32.73

32.82

65.76

47.88
20.60
$2.50 \quad 0.49$

$\begin{array}{llll}11.78 & 27.07 & 2.42 & 1.42\end{array}$

$14.93 \quad 37.32$

$2.81 \quad 1.41$

$14.29 \quad 6.01$

$\begin{array}{ll}1.87 & 0.9\end{array}$

$11.75 \quad 9.00$

$1.79 \quad 1.06$

$17.00 \quad 14.75$

$2.17 \quad 1.18$

$11.72 \quad 57.10$

$3.45 \quad 1.4$

$19.29 \quad 57.11$

$3.48 \quad 1.27$

$16.07 \quad 51.27$

$3.26 \quad 1.38$

$10.28 \quad 28.82$

$2.48 \quad 1.49$

$\begin{array}{ll}2.50 & 0.68\end{array}$

$27.25 \quad 22.36$

$2.65 \quad 1.13$

$2.34 \quad 1.24$

$2.29 \quad 1.21$

$13.53 \quad 19.55$

$2.47 \quad 1.24$

$23.00 \quad 22.25$

$1.91 \quad 1.06$

$8.96 \quad 10.69$

$3.85 \quad 1.36$

$7.04 \quad 72.36$

$2.5 \quad 1.29$

$19.44 \quad 24.29$

$3.62 \quad 1.33$

$13.32 \quad 63.82$

$3.57 \quad 1.44$

$3.15 \quad 0.70$

\begin{tabular}{l}
$18.80 \quad 39.60$ \\
\hline
\end{tabular}

$2.92 \quad 1.39$

$2.94 \quad 1.35$

$3.43 \quad 1.4$

$15.05 \quad 57.40$

$2.97 \quad 1.29$

$22.22 \quad 39.65$

$3.15 \quad 1.4$

$13.84 \quad 51.43$

$2.53 \quad 1.25$

$\begin{array}{ll}16.33 & 25.37\end{array}$

$2.34 \quad 1.18$

$17.63 \quad 19.65$

$2.6 \quad 1.25$

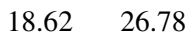

$3.12 \quad 1.16$

$29.41 \quad 37.85$

$3.29 \quad 1.32$

$18.18 \quad 48.99$

$2.90 \quad 0.67$

$13.15 \quad 21.09$

$2.36 \quad 1.22$

$21.45 \quad 30.67$

$2.78 \quad 1.23$ 
Table 1 continued

\begin{tabular}{|c|c|c|c|c|c|}
\hline Item & $\begin{array}{l}\text { Strongly } \\
\text { agree/agree } \\
(\%)\end{array}$ & $\begin{array}{l}\text { Neutral } \\
(\%)\end{array}$ & $\begin{array}{l}\text { Disagree/strongly } \\
\text { disagree }(\%)\end{array}$ & Mean & SD \\
\hline $\begin{array}{l}\text { As far as possible, mental health services should be provided through community } \\
\text { based facilities (CMHI3) }\end{array}$ & 45.87 & 30.33 & 23.81 & 2.7 & 1.12 \\
\hline $\begin{array}{l}\text { Locating mental health services in residential neighbourhoods does not endanger } \\
\text { local residents (CMHI4) }\end{array}$ & 44.88 & 21.95 & 33.17 & 2.85 & 1.25 \\
\hline $\begin{array}{l}\text { Residents have nothing to fear from people coming into their neighbourhood to } \\
\text { obtain mental health services (CMHI5) }\end{array}$ & 53.75 & 26.25 & 20.00 & 2.54 & 1.09 \\
\hline Mental health facilities should be kept out of residential neighbourhoods (CMHI6) & 39.80 & 17.88 & 42.32 & 2.95 & 1.31 \\
\hline $\begin{array}{l}\text { Local residents have good reason to resist the location of mental health services in } \\
\text { their neighbourhood (CMHI7) }\end{array}$ & 34.11 & 24.29 & 41.60 & 2.99 & 1.1 \\
\hline $\begin{array}{l}\text { Having mental patients live within residential neighbourhoods might be good } \\
\text { therapy but the risks for the residents are too great (CMHI8) }\end{array}$ & 54.75 & 25.75 & 19.50 & 2.47 & 1.18 \\
\hline $\begin{array}{l}\text { It is frightening to think of people with mental problems living in residential } \\
\text { neighbourhoods (CMHI9) }\end{array}$ & 50.62 & 24.81 & 24.56 & 2.61 & 1.17 \\
\hline $\begin{array}{l}\text { Locating mental health facilities in a residential area downgrades the } \\
\text { neighbourhood (CMHI10) }\end{array}$ & 36.50 & 15.75 & 47.75 & 3.07 & 1.43 \\
\hline
\end{tabular}

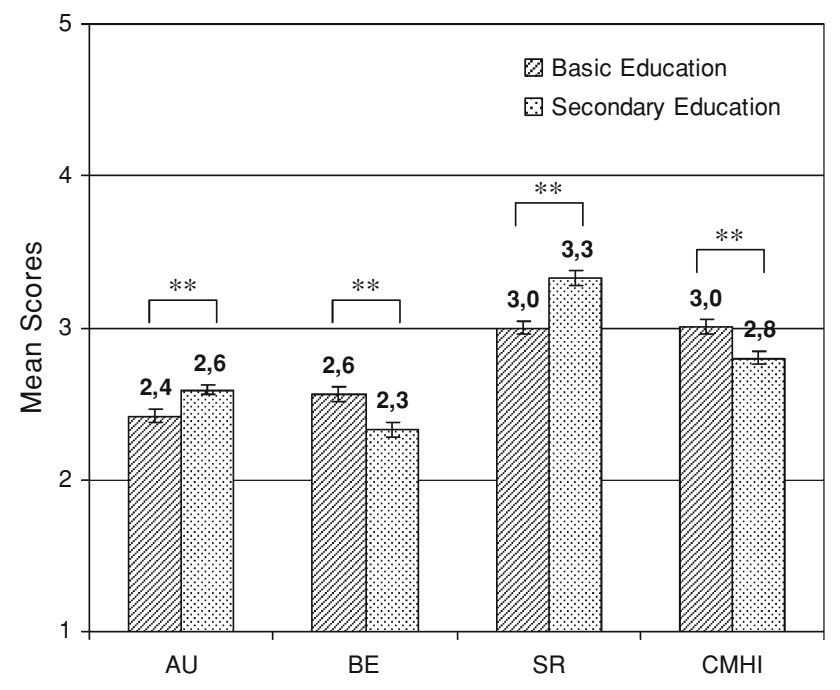

Fig. 1 Mean Scores of the CAMI subscales as a function of educational level (basic education $n=162$, secondary education $n=332$ ). Higher scores indicate higher disagreement. Error bars show standard errors, $* * p<.005$

people. $79.1 \%$ of the patients agreed that most people think less of a person who had been to a mental hospital (PDD7) and $85.7 \%$ felt that the opinions of such a person were taken less seriously (PDD12), they were regarded as less intelligent $(70.5 \%$, PDD2) and less trustworthy (65.7\%, PDD3). More than half of the patients agreed that most people believe that entering a mental hospital is a sign of personal failure (PDD5). As far as the perceived personal distance of other people to persons with a mental disorder is concerned, it was believed by $80.0 \%$ of patients that most young women would be reluctant to marry a man who had been hospitalized for a serious mental disorder (PDD11), 58.1\% did not think that a former mental patient would be accepted as a close friend by most people (PDD1). The perceived discrimination extended also to employment chances: $77.2 \%$ of the patients agreed that most employers would pass over an application of a former mental patient in favour of another applicant (PDD9).

As far as coping strategies were concerned, widespread agreement was found that it is advisable to conceal that one had suffered from a mental illness. Most items recommending secrecy prompted assent from more than $70 \%$ of the patients (SE1, 2, 3, 6, 8, 9). 80.3\% of those who answered this item would encourage other members of their family to keep their (the patient's) mental illness a secret (SE7).

Regarding withdrawal as a possible coping mechanism, the picture is less homogeneous. A majority of patients preempted rejection by avoiding people if they thought someone thought less of them because they had been in psychiatric treatment $(68.9 \%$, WI4) or someone held negative opinions about psychiatric patients in general $(60.0 \%$, WI1). In terms of general social contact, 40.4-49.0\% thought that it is generally better, easier or less stressful for persons with mental illness to socialize among themselves (WI5, 6, 7, 13). The strongest agreement $(70.5 \%)$ was recorded for the view that places of work should be organized in such a way as to allow people who have experienced mental illness to work together (WI2).

\section{Sex and age}

In order to examine whether men and women differed with regard to perceived discrimination and devaluation or with 
Table 2 Percentages of affirmative answers for the items of the PDD, SE and WI for the patients

\begin{tabular}{|c|c|c|}
\hline Item & $\begin{array}{l}\text { Agree } \\
(\%)\end{array}$ & $N$ \\
\hline Perceived discrimination and devaluation ${ }^{\mathrm{a}}$ & 66.11 & 1 \\
\hline Most people would accept a former mental patient as a close friend (PDD1) & 41.90 & \\
\hline Most people believe that a person who has been in a mental hospital is just as intelligent as the average person (PDD2) & 29.52 & 1 \\
\hline Most people believe that a former mental patient is just as trustworthy as the average citizen (PDD3) & 34.29 & 1 \\
\hline Most people would accept a former mental patient as a teacher of young children in a public school (PDD4) & 58.65 & 1 \\
\hline Most people believe that entering a mental hospital is a sign of personal failure (PDD5) & 53.85 & 10 \\
\hline $\begin{array}{l}\text { Most people would not hire a former mental patient to take care of their children, even if he or she had been well for some } \\
\text { time (PDD6) }\end{array}$ & 78.85 & \\
\hline Most people think less of a person who has been in a mental hospital (PDD7) & 79.05 & 1 \\
\hline Most employers will hire a former mental patient if he or she is qualified for the job (PDD8) & 48.08 & \\
\hline Most employers will pass over the application of a former mental patient in favour of another applicant (PDD9) & 77.23 & \\
\hline Most people in my community would treat a former mental patient just as they would treat anyone (PDD10) & 47.62 & \\
\hline Most young women would be reluctant to date a man who has been hospitalized for serious mental disorder (PDD11) & 80.00 & \\
\hline Once they know a person was in a mental hospital, most people will take his or her opinion less seriously (PDD12) & 85.71 & 10 \\
\hline Secrecy ${ }^{\mathrm{b}}$ & 71.74 & 10 \\
\hline $\begin{array}{l}\text { If you had a closer relative who had been treated for a serious mental illness, you would advise him or her not to tell anyone } \\
\text { about it (SE1) }\end{array}$ & 75.00 & 10 \\
\hline $\begin{array}{l}\text { If you were in treatment for a serious mental illness you would worry about certain people finding out about your treatment } \\
\text { (SE2) }\end{array}$ & 74.29 & 10 \\
\hline If you have ever been treated for a serious mental illness, the best thing to do is to keep it a secret (SE3) & 75.96 & 10 \\
\hline There is no reason for a person to hide the fact that he or she was a mental patient at one time (SE4) & 45.63 & 10 \\
\hline $\begin{array}{l}\text { In view of society's negative attitudes toward people with serious mental illnesses, you would advise people with serious } \\
\text { mental illness to keep it a secret (SE5) }\end{array}$ & 65.05 & 10 \\
\hline In order to get a job a former mental patient will have to hide his or her history of hospitalization (SE6) & 75.00 & 10 \\
\hline You encourage other members of your family to keep your mental illness a secret (SE7) & 80.26 & 7 \\
\hline $\begin{array}{l}\text { You believe that a person who has recovered from a mental illness experienced earlier in life should not tell other people about } \\
\text { it (SE8) }\end{array}$ & 70.48 & 10 \\
\hline $\begin{array}{l}\text { When you meet people for the first time, you make a special effort to keep the fact that you have been in psychiatric treatment } \\
\text { to yourself (SE9) }\end{array}$ & 78.85 & 10 \\
\hline Withdrawal $^{\mathrm{c}}$ & 51.80 & 10 \\
\hline If you thought that someone you knew held negative opinions about psychiatric patients, you would avoid him or her (WI1) & 60.00 & 10 \\
\hline Places of work should be organized so that people who have experienced a severe mental illness can work together (WI2) & 70.48 & 10 \\
\hline It is easier for you to be friendly with people who have been psychiatric patients (WI3) & 41.90 & 10 \\
\hline If a person thought less of you because you had been in psychiatric treatment, you would avoid him or her (WI4) & 68.93 & 10 \\
\hline $\begin{array}{l}\text { People who have had a serious mental illness will find it less stressful to socialize with people who have also had a serious } \\
\text { mental illness (WI5) }\end{array}$ & 43.27 & 10 \\
\hline $\begin{array}{l}\text { If a friend of yours developed a serious mental illness you would advise him or her to spend most of his or her free time with } \\
\text { people who also have a serious mental illness (WI6) }\end{array}$ & 40.38 & 10 \\
\hline $\begin{array}{l}\text { You believe that people who have a serious mental illness feel most comfortable when they are with people who also have a } \\
\text { serious mental illness (WI7) }\end{array}$ & 49.02 & 102 \\
\hline You have a lot in common with people who have experienced a serious mental illness (WI8) & 40.78 & 103 \\
\hline
\end{tabular}

Percentages refer to the number of persons who answered the item

${ }^{a}$ Proportion of answers in the sense of the construct PDD. Items with reverse scoring: 1, 2, 3, 4, 8, 10

b Proportion of answers in the sense of the construct SE. Item with reverse scoring: 4

${ }^{c}$ Proportion of answers in the sense of the construct WI. No items with reverse scoring

respect to the coping strategies of secrecy and withdrawal, the subscale means for men (PDD, $0.67 \pm 0.24$; SE, $0.73 \pm 0.28 ; \quad$ WI, $0.49 \pm 0.23$ ) and women (PDD,
$0.66 \pm 0.23 ;$ SE, $0.68 \pm 0.28 ;$ WI, $0.57 \pm 0.24$ ) were compared by means of independent $t$ tests. No differences were observed (all $p \mathrm{~s}>0.10$ ). 
The influence of age on the subscales PDD, SE and WI was investigated by calculating correlations between age and the subscale means. No correlations were found (all $p s>0.10)$.

\section{Discussion}

Population attitudes

We investigated attitudes of an urban population in Southern Ghana with regard to mental illness and mentally ill people and found a heterogeneous picture. With respect to the nature and causes of mental illness negative views prevailed. Although the majority of respondents thought that nobody had the right to exclude mentally ill persons from their neighbourhood, they also felt that their presence might pose a risk and many people would not want to live next to a person with mental illness. Mental health services in the community by contrast were seen in a more positive light. This apparent discrepancy might perhaps be related to the scarcity of resources and the presence of a treatment gap of $98 \%$ [39] with regard to mental illness. One might speculate whether the questions about living next door to mentally ill persons tended to evoke the picture of a "typical", i.e. untreated person, whereas locating services in an area was regarded as less problematic or even an improvement.

With regard to mentally ill persons in general and the society's attitude towards them, benevolent views tended to prevail and the responsibility of providing the best possible care was acknowledged by a large majority. More than $40 \%$ of the respondents, however, saw no problem with denying mentally ill persons their individual rights.

Sex and age were at best weakly related to the attitudes. With regard to sex we found that women held slightly more authoritarian views. A very weak influence of age was found in so far as older persons tended to be slightly less socially restrictive. However, the correlation, although statistically significant, only explains $1.7 \%$ of the variance and needs replication by further studies before an interpretation seems warranted, especially since the direction of the association is not as one would expect on the basis of other research in this area [5].

A better education was accompanied by more positive attitudes towards mentally ill persons across all subscales. The effects were small to moderate and were in line with previous research in several parts of the world [5] as well as in sub-Saharan Africa [11, 23]. However, a study in Nigeria failed to find any such connection [14].

The general level of stigma found is comparable to that reported by Ngissah for Ghana 35 years ago [24]. Three items were included in his study that allow a cautious comparison with our data and support the view that the attitudes have not changed much. In Ngissah's sample more participants $(39.6 \%)$ agreed that mental illness is an illness like any other (our sample: $31.2 \%$ ) and fewer of his participants $(43.6 \%)$ saw lack of moral strength and will power as a cause of mental illness (our sample: $61.2 \%$ ), whereas $78.9 \%$ of Ngissah's Ghanaian participants felt that patients in mental hospitals were like children $(68.3 \%$ of our sample believed they needed the same kind of control as children do). In the interpretation, the differing instruments used should be taken into account as well as the fact that Ngissah's sample consisted of students only and thus represents the views of persons with a higher educational background than our sample.

Comparing our results with more recent studies from other sub-Saharan countries, the Ghanaian population appeared to have a more positive attitude than the Nigerian nurses and journalists questioned by Abasiubong and coworkers [1]. The authors do not list the frequencies for all CAMI items, but judging from those where the frequencies are provided, both, the Nigerian nurses and journalists, expressed markedly less benevolent views than we encountered among the Ghanaian participants. These differences were found in spite of the fact that the Nigerian sample had a higher educational background by virtue of their occupations. Further studies of social distance towards persons with mental illness in the Nigerian population confirmed the high levels of social distance regardless of educational attainment [2, 14].

If one compares the attitudes we observed in Ghana with attitudes among the German population reported by Angermeyer and colleagues [6], the Ghanaian participants held more authoritarian and socially restrictive views, were less benevolent towards persons with mental illness and also less supportive of the community mental health ideology. The result of this comparison agrees with the findings of Ngissah, who also found a less favourable attitude towards persons with mental illness among the Ghanaian students as compared to US American students [24], and reflects the more general observation that stigma tended to be higher in developing than in developed countries [4].

When interpreting the results of the CAMI, it should be taken into account that some of the items may have different meanings and implications in a country in which psychiatric services are still rudimentary and a treatment gap with regard to psychiatric disorders of $98 \%$ was identified by the WHO. Items such as "there is something about mentally ill people that makes them easy to tell from normal people" may not simply express stigmatising attitudes on part of the respondents, but also reflect the reality in a context where psychiatric treatment is the exception rather than the rule and even severe disorders remain untreated for prolonged periods of time. The same is true 
for the perceived dangerousness of persons with mental illness; untreated illness might lead to a higher rate of agitated, disruptive or aggressive behaviour, capable of frightening persons witnessing such episodes. Unmet needs, rather than authoritarianism might also inform the answers to items such as "as soon as a person shows signs of mental disturbance he should be hospitalized"; what in an affluent society of developed countries might be the authoritarian wish to have the person removed to a hospital, could well be the expression of the wish that such help be available when needed in a less developed country. These context-related factors may have also influenced the internal consistencies of the instruments used, given that the instruments were developed and validated in developed countries.

The CAMI questionnaire uses the abstract term "mental illness", which might not be familiar to lay persons. In order to learn a little more about what our participants associated with this term, we asked each participant at the end of the interview the open question: "What, to the best of your knowledge, causes mental illness?" The answers confirmed that the participants were familiar with this term. It is however possible, that the participants might have had a more limited range of disorders in mind when they answered the items than are normally subsumed under this broad category. In particular, they might have pictured psychotic persons, since this was the condition most readily recognized as mental illness by a comparable sample in Deribew's and Tamirat's vignette study [11].

\section{Patients: perceived stigma}

The patients perceived extensive stigma. They felt devalued, experienced large social distance and expected to be discriminated against when looking for work. Consequently, concealment of one's illness was a major concern of the respondents and secrecy a universally employed coping mechanism. In addition, withdrawal from social contacts, particularly those where a negative attitude was suspected, was practised by the majority of the persons interviewed.

The majority of the patients were men $(72.8 \%)$. This does not reflect a sampling bias, but the proportion of men among the patients at the time of the survey. The fact that in sub-Saharan Africa men are overrepresented in psychiatric hospitals has been described repeatedly [12]. Franklin et al. [12] discussed possible reasons for the high proportion of men and concluded that they lie in sex differences with regard to service utilization rather than differing prevalences of mental disorders.

The high level of perceived stigma found in the present study is in line with the scant data from other sub-Saharan countries [9]. In Botha et al.'s [9] South African sample more than half of the patients stated that they avoided getting close to persons who do not have a mental illness to avoid rejection. This corresponds well with the range of social withdrawal reported by our participants.

To the authors' knowledge there are no other studies presenting data regarding the stigma perceived by mentally ill persons from African countries. A couple of studies can be said to contribute to the question at hand in a more indirect way. Ssebunnya et al. [34] interviewed mental health stakeholders in Uganda, among them user advocacy organisations. They reported that most stakeholders, including the members of the users' groups, perceived high stigmatisation of mental illness and a vicious circle of poverty and mental illness. Shibre and coworkers [32] investigated the perception of stigma not among the mentally ill patients, but among their family members $(n=178)$ in rural Ethiopia, estimating the prevalence of experienced stigma at $75 \%$, with about $40 \%$ of respondents worried that other people would know about their family member's illness, being worried that they might be treated differently on account of it and feeling the need to hide the illness from others.

\section{Limitations}

In interpreting these results, the limitations of the present study should be taken into account. The population data presented are based on a convenience sample recruited in urban areas in the South of Ghana. The participants were mostly members of the Akans ethnic group. The views expressed may not be generalized; in particular, they might not reflect the views of Ghanaians in the Northern regions or rural areas.

Two items were omitted from the CAMI and the items of the CAMI were phrased so as to ask in a generic way about "mental illness". They did not differentiate between different diagnoses. It is therefore possible that people's attitudes were not the same for all mental disorders. Furthermore, the items might take on a different meaning in the context of a developing country with few psychiatric resources available to the population.

Regarding the patients, the data presented are based on persons who were at the time of the interview patients of Ghana's public psychiatric hospitals. As there are only three such hospitals in Ghana, conclusions about Ghanaian psychiatric hospital patients may be warranted on the basis of our results. However, generalizations about mentally ill persons in Ghana in general may not be drawn from the data as due to the scarcity of resources, the admission to such a hospital is itself subject to many factors and selection processes.

\section{Conclusion}

We presented data on population attitudes towards mental illness in Southern Ghana and perceived stigma among 
patients of Ghana's three psychiatric hospitals. Our results showed that a high level of stigma prevails in the population and is also perceived as such by the persons suffering from mental illness. These attitudes coexist with more benevolent tendencies towards mentally ill persons, such as support for spending taxes on better treatments and care. Efforts should be undertaken to address the negative views by anti-stigma programmes, perhaps by building on the more benevolent attitudes. Equally important will be a reduction of the treatment gap and improved access to psychiatric care for mentally ill persons; the experience that mental illnesses can be successfully treated may also decrease the stigma attached to such illnesses. In a more indirect way, improvements in the educational sector and increased literacy may also contribute to more favourable attitudes towards mentally ill persons.

The high level of perceived stigma observed among the patients underscores the importance of anti-stigma interventions that focus not only on the public, but also on the affected persons.

Acknowledgments The authors are grateful to Philip Abepuoring, Evans Akose, Nana Banyin, Jeffery Koranteng and Samuel Nyarko for help with data collection and to Lena Bläsing, Dennis Golm, Mira Holzer, Anne Meinhardt-Renner, Nele Nyenhuis, Jutta Stahl and two anonymous reviewers for helpful comments on this manuscript.

Open Access This article is distributed under the terms of the Creative Commons Attribution Noncommercial License which permits any noncommercial use, distribution, and reproduction in any medium, provided the original author(s) and source are credited.

\section{References}

1. Abasiubong F, Ekott JU, Bassey EA (2007) A comparative study of attitude to mental illness between journalists and nurses in Uyo, Nigeria. Afr J Med Med Sci 36:345-351

2. Adewuya AO, Makanjuola ROA (2005) Social distance towards people with mental illness amongst Nigerian university students. Soc Psychiatry Psychiatr Epidemiol 40:865-868. doi:10.1007/ s00127-005-0965-3

3. Adewuya AO, Makanjuola ROA (2008) Social distance towards people with mental illness in southwestern Nigeria. Aust NZ J Psychiatry 42:389-395. doi:10.1080/00048670801961115

4. Alonso J, Buron A, Bruffaerts R, He Y, Posada-Villa J, Lepine J, Angermeyer MC et al (2008) Association of perceived stigma and mood and anxiety disorders: Results from the World Mental Health Surveys. Acta Psychiatr Scand 118:305-314. doi:10.1111/j. 1600-0447.2008.01241.x

5. Angermeyer MC, Dietrich S (2006) Public beliefs about and attitudes towards people with mental illness: A review of population studies. Acta Psychiatr Scand 113:163-179. doi:10.1111/j. 1600-0447.2005.00699.x

6. Angermeyer MC, Heiss S, Kirschenhofer S, Ladinser E, Löffler W, Schulze B, Swiridoff M (2003) Die deutsche Version des Community-Attitudes-toward-the-Mentally-Ill (CAMI)-Inventars [The German version of the Community-Attitudes-Toward-theMentally-Ill (CAMI) inventory]. Psychiatr Prax 30:202-206
7. Asenso-Okyere W (1998) Cost recovery in Ghana: are there any changes in health care seeking behaviour? Health Policy Plan 13:181-188. doi:10.1093/heapol/13.2.181

8. Atindanbila S (2000) Patients' perceptions of the quality of psychiatric services: a study at the Accra Psychiatric Hospital. MPhil thesis, University of Ghana

9. Botha UA, Koen L, Niehaus DJH (2006) Perceptions of a South African schizophrenia population with regards to community attitudes towards their illness. Soc Psychiatry Psychiatr Epidemiol 41:619-623. doi:10.1007/s00127-006-0071-1

10. Corrigan PW, Edwards AB, Green A, Diwan SL, Penn DL (2001) Prejudice, social distance, and familiarity with mental illness. Schizophr Bull 27:219-225

11. Deribew A, Tamirat Y (2005) How are mental health problems perceived by a community in Agaro town? Ethiop J Health Dev 19:153-159

12. Franklin RR, Sarr D, Gueye M, Sylla O (1996) Cultural response to mental illness in Senegal: Reflections through patient companions-Part I. Methods and descriptive data. Soc Sci Med 42:325-338. doi:10.1016/0277-9536(95)00108-5

13. Graf J, Lauber C, Nordt C, Rüsch P, Meyer PC, Rössler W (2004) Perceived stigmatization of mentally ill people and its consequences for the quality of life in a Swiss population. J Nerv Ment Dis 192:542-547

14. Gureje O, Lasebikan VO, Ephraim-Oluwanuga O, Olley BO, Kola L (2005) Community study of knowledge of and attitude to mental illness in Nigeria. Br J Psychiatry 186:436-441. doi: 10.1192/bjp.186.5.436

15. Jacob K, Sharan P, Mirza I, Garrido-Cumbrera M, Seedat S, Mari J, Sreenivas V et al (2007) Mental health systems in countries: where are we now? Lancet 370:1061-1077. doi:10.1016/S01406736(07)61241-0

16. Laugharne R, Burns T (1999) Mental health services in Kumasi, Ghana. Psychiatr Bull 23:361

17. Lefley HP (1989) Family burden and family stigma in major mental illness. Am Psychol 44:556-560. doi:10.1037/0003066X.44.3.556

18. Link BG, Cullen FT, Struening EL, Shrout PE (1989) A modified labeling theory approach to mental disorders: An empirical assessment. Am Sociol Rev 54:400-423. doi:10.2307/2095613

19. Link BG, Mirotznik J, Cullen FT (1991) The effectiveness of stigma coping orientations: can negative consequences of mental illness labeling be avoided? J Health Soc Behav 32:302-320. doi: $10.2307 / 2136810$

20. Link BG, Phelan JC (2001) Conceptualizing stigma. Annu Rev Sociol 27:363-385. doi:10.1146/annurev.soc.27.1.363

21. Link BG, Struening EL, Neese-Todd S, Asmussen S, Phelan JC (2001) Stigma as a barrier to recovery: the consequences of stigma for the self-esteem of people with mental illnesses. Psychiatr Serv 52:1621-1626

22. Link BG, Struening EL, Neese-Todd S, Asmussen S, Phelan JC (2002) On describing and seeking to change the experience of stigma. Psychiatr Rehabil Skills 6:201-231

23. Mulatu MS (1999) Perceptions of mental and physical illnesses in north-western Ethiopia: causes, treatments, and attitudes. J Health Psychol 4:531-549. doi:10.1177/135910539900400407

24. Ngissah P (1975) A comparative study of attitudes towards mental illness. MA thesis, California State University

25. Perlick DA, Rosenheck RA, Clarkin JF, Sirey JA, Salahi J, Struening EL, Link BG (2001) Stigma as a barrier to recovery: adverse effects of perceived stigma on social adaptation of persons diagnosed with bipolar affective disorder. Psychiatr Serv 52:1627-1632. doi:10.1176/appi.ps.52.12.1627

26. Quinn N (2007) Beliefs and community responses to mental illness in Ghana: the experiences of family carers. Int $\mathrm{J}$ Soc Psychiatry 53:175-188 
27. Roberts H (2001) A way forward for mental health care in Ghana? Lancet 357:1859

28. Rosenberg D (2002) It also takes a village. Developing community mental health. Int Soc Work 45:305-314

29. Rosenfield S (1997) Labeling mental illness: the effects of received services and perceived stigma on life satisfaction. Am Sociol Rev 62:660-672. doi:10.2307/2657432

30. Rüsch N, Angermeyer MC, Corrigan PW (2005) Mental illness stigma: concepts, consequences, and initiatives to reduce stigma. Eur Psychiatry 20:529-539. doi:10.1016/j.eurpsy.2005.04.004

31. Schomerus G, Matschinger H, Angermeyer MC (2009) The stigma of psychiatric treatment and help-seeking intentions for depression. Eur Arch Psychiatry Clin Neurosci 259:298-306. doi: 10.1007/s00406-009-0870-y

32. Shibre T, Negash A, Kullgren G, Kebede D, Alem A, Fekadu A, Fekadu D et al (2001) Perception of stigma among family members of individuals with schizophrenia and major affective disorders in rural Ethiopia. Soc Psychiatry Psychiatr Epidemiol 36:299-303. doi:10.1007/s001270170048

33. Sodzi-Tetteh S (2007) Just don't get mad in Ghana. http://www. modernghana.com/blogs/142593/31/just-dont-get-mad-in-ghana. html. Accessed 30 January 2010
34. Ssebunnya J, Kigozi F, Lund C, Kizza D, Okello E (2009) Stakeholder perceptions of mental health stigma and poverty in Uganda. BMC Int Health Hum Rights 9:5

35. Stuart H (2006) Mental illness and employment discrimination. Curr Opin Psychiatry 19:522-526

36. Taylor SM, Dear MJ (1981) Scaling community attitudes toward the mentally ill. Schizophr Bull 7:225-240

37. Vogel DL, Wade NG, Hackler AH (2007) Perceived public stigma and the willingness to seek counseling: the mediating roles of self-stigma and attitudes toward counseling. J Couns Psychol 54:40-50. doi:10.1037/0022-0167.54.1.40

38. Welch B (1938) The significance of the difference between two means when the population variances are unequal. Biometrika $29: 350-362$

39. WHO (2007) Ghana: a very progressive mental health law. The country summary series. http://www.who.int/mental_health/policy/ country/GhanaCoutrySummary_Oct2007.pdf. Accessed 30 January 2010 